\title{
Editorial: Emerging Frontiers in Ecological Stoichiometry
}

\author{
Michelle A. Evans-White ${ }^{1 *}$, Zoe G. Cardon ${ }^{2}$, Jennifer A. Schweitzer ${ }^{3}$, Jotaro Urabe ${ }^{4}$ and \\ James J. Elser ${ }^{5}$ \\ ${ }^{1}$ Department of Biological Sciences, University of Arkansas, Fayetteville, AR, United States, ${ }^{2}$ Ecosystems Center, Marine \\ Biological Laboratory, Woods Hole, MA, United States, ${ }^{3}$ Ecology and Evolutionary Biology, University of Tennessee, \\ Knoxville, Knoxville, TN, United States, ${ }^{4}$ Graduate School of Life Sciences, Tohoku University, Sendai, Japan, ${ }^{5}$ Flathead Lake \\ Biological Station, University of Montana, Polson, MT, United States
}

Keywords: ecological stoichiometry, biological stoichiometry, global change, human health, cryosphere, eco-evo, silica, soil organic matter

\section{Editorial on the Research Topic}

Emerging Frontiers in Ecological Stoichiometry

\section{WHAT IS STOICHIOMETRY AND WHY IS IT RELEVANT FOR GLOBAL CHANGE?}

The ecological (ES) and biological stoichiometry (BS; Elser et al., 2000) theoretical frameworks apply mass balance of energy and multiple chemical elements to fluxes at multiple scales of biological organization and integrate them into an evolutionary framework. The unprecedented rate of global change (GC) paired with future models of change that may occur unless anthropogenic impacts are mitigated (Easterling et al., 2000; Coumou and Rahmstorf, 2012; IPCC,

OPEN ACCESS

Edited and reviewed by: Elise Huchard

UMR5554 Institut des Sciences de l'Evolution de Montpellier (ISEM), France

*Correspondence: Michelle A. Evans-White mevanswh@gmail.com

Specialty section

This article was submitted to Behavioral and Evolutionary Ecology,

a section of the journal

Frontiers in Ecology and Evolution

Received: 11 October 2019 Accepted: 18 November 2019 Published: 05 December 2019

Citation:

Evans-White MA, Cardon ZG Schweitzer JA, Urabe $J$ and Elser $J J$ (2019) Editorial: Emerging Frontiers in Ecological Stoichiometry.

Front. Ecol. Evol. 7:463. doi: 10.3389/fevo.2019.00463 2018) necessitates rapid global human innovation and social change to avoid various emerging perils (Figueres et al., 2017; IPCC, 2018; UNCC, 2019). The ES/BS framework can represent a powerful tool to drive the innovation needed to address these GC perils (Urabe et al., 2010).

\section{WOODSTOICH 15TH AND WOODSTOCK 50TH-TWO ANNIVERSARIES OF YOUTHFUL INNOVATION}

Within this perilous global context and on the 15 and 50th anniversary of the first Woodstoich Workshop (WW; August 2004) and the famous Woodstock festival, respectively, the 4th WW convened from 15 to 19 August 2019 at Flathead Lake Biological Station in Montana, USA. The WWs aim to produce a collection of publications that innovate and expand the use of ES/BS theory. The WWs take inspiration from the Woodstock festival (August 15-17 1969) where young people caught up in a time of war and turbulent politics came together in a short, energetic musical event espousing unity, peace, and love to create a lasting legacy. Three previous WW events have taken place (Hessen and Elser, 2005; Urabe et al., 2010; Sterner et al., 2015), but the sense of urgency for unity and innovative solutions to address GC issues facing the young Woodstoich participants has never been greater than in 2019 (e.g., Hagedorn et al., 2019).

\section{WHAT IS THE WOODSTOICH CONTRIBUTION?}

Woodstoich speeds the pace of development and communication of scientific ideas; international, collaborative ties among early-career scientists (graduate students, post-docs, pre-tenured professors) with common research interests are established, and the participants' innovative ideas are transformed into a peer-reviewed publication in less than 6-7 months. Five group leaders 
were chosen in December 2018 based on manuscript proposals submitted with their applications. Leaders then selected team members by April 2019 based on applications that demonstrated a combination of common interest and the skill set required to complete the proposed manuscript. Groups worked on manuscripts remotely using shared, cloud-based applications for $\sim 4$ months prior to the workshop and then, in keeping with the Woodstock concept, these innovative, young minds all came together for an intellectual jam session in the form of the 6-days workshop in August 2019. During that short time, groups networked, interacted with a few senior scientist "mentorsages" invited by group-leader consensus, and then finalized and submitted manuscripts for a pre-arranged, extremely-rapid review; a 24-h turnaround was requested from three outside reviewers recruited by Associate Editors prior to the event. Groups responded to reviews during the remainder of the workshop with the goal of obtaining provisional acceptance of manuscripts prior to departing for their home institutions.

Additionally, innovation is stimulated by bringing together young minds from diverse backgrounds whose mindsets are not locked into place by long-term tradition or professional relationships and by encouraging them to embrace the unique spirit of the workshop. Contributing to that spirit are the Three Rules of Woodstoich, about which all participants were briefed in a kickoff session. Rule 1: Obey the law. Which law? The Law of Conservation of Matter applied across multiple chemical elements. Development of stoichiometric theory has revealed significant implications of constraining ecological dynamics within such bounds, enabling insight into the feasibility envelope for eco-evolutionary systems. Rule 2: Question authority. While senior experts on ES/BS were in attendance at the event (and indeed lurking in the reviewer pool), participants were strongly encouraged to hold ES/BS paradigms up to the light and challenge them as necessary. Rule 3: Make it groovy. All were urged to follow the spirit of Woodstock, to do their best to say something different, to be bold, and to try to forge a new path of innovation on their paper's topic. Here we summarize the papers produced under this charge.

\section{Linking Genetic Variation and Stoichiometric Traits}

Lemmen et al. examines potential importance of genetic variations in eco-evolutionary dynamics using existing data of common garden experiments for various organisms. They found that genetic variations in some of stoichiometric traits were substantial, suggesting that single species have various options in a way of mass balance for maintaining their elemental composition. These findings suggest a new direction for understanding the role of ES in eco-evolutionary dynamics.

\section{Ecological Stoichiometry of the Mountain Cryosphere}

Ren et al. reviews nutrient and trophic stoichiometry in mountain glacial ecosystems and finds strong potential for nutrient limitation, especially by phosphorus, that is likely transmitted through the limited, but surprising, food webs of organisms living on and near glaciers. Mountain glaciers are less nutrient-limited, however, than the better-known ice sheets of Antarctica, making predictions of one landscape to another inadvisable. In a warming world with increased ice melting, nitrogen and phosphorus limitations are predicted to increase with implications for downslope organisms, including humans.

\section{Elemental Ratios Link Environmental Change and Human Health}

Paseka et al. leaps across disciplinary boundaries to argue for the importance of a stoichiometric perspective in identifying the roots of a range of issues for human health. Building from a handful of examples in the literature where stoichiometric ratios of elements have clear effects on the health of human or animal models, Paseka et al. point to further links between ecological stoichiometry and pressing issues ranging from food quality and water security to human susceptibility to non-infectious and infectious disease.

\section{Stoichiometry in Soil Organic Matter Models}

Buchkowski et al. presents a review and new soil organic matter (SOM) model that uses stoichiometry of plants and microorganisms to show how incorporation of mass balance information (including ratios of carbon, nitrogen, phosphorus, and sulfur) constrain SOM models to probable fluxes across landscapes, a perspective that is missing in current SOM models. A stoichiometric approach to SOM models adds boundaries to flux estimates that provides critical realism to models of carbon stability that substantially reduce uncertainty and will allow for more robust carbon accounting in a changing world.

\section{Silica Stoichiometry in a Large Floodplain River}

In a powerful new analysis of diverse components of the Upper Mississippi River System, Carey et al. identifies dominant controls and constraints over silicon:nitrogen:phosphorus $(\mathrm{Si}: \mathrm{N}: \mathrm{P})$ ratios that are fundamental to determining phytoplankton assemblages in fresh and marine receiving waters. Distinct drivers, from backwater residence time to north-south gradients in lithology and human land use, set the stage for shifting Si:N:P ratios, which, in turn, have the potential to result in cascading effects on food-web structure and carbon sequestration.

\section{CONCLUSION AND PERSPECTIVES}

In 2054, Woodstoich may mark its own 50th anniversary (WW10). Likely its founders will have passed from the earthly scene by then and time will tell if the concept of Woodstoich or even of ES will persist for that long. Let's imagine that they do and that WW10 organizers do a better job than the Woodstock 50th concert organizers (who canceled the anniversary concert). What will the world of 2050 be like and how would the WW4 have to be re-written at WW10 to account for the world of 2050 ? 
Thinking about Lemmens et al., we would ask: how much evolution will have taken place? Was it fast enough to accommodate the rapid biogeochemical and climatic changes underway? How much more will we be able to discover about that evolution given 30 more years of innovation in genomic tools? Will a re-write of Ren et al. have to account for massive global glacier loss if climate targets are not met? Or will the paper be describing the biogeochemical and ecological dynamics of reduced but stabilized glaciers in mountain regions? Of great relevance to a new version of Paseka et al. will be what emissions pathway we follow during the next 30 years. If we follow the high emissions pathway (Riahi et al., 2011), $\mathrm{pCO}_{2}$ will be 550 ppm. What will this imply for the nutritional quality of crops? Will fertilization rates have been amplified in order to lower C:N and C:P and C:essential metal ratios, with implications for water quality and its associated health impacts? Soils hold tremendous potential to sequester (or release) carbon during the coming decades. Will stoichiometric approaches such as those described by Buchowski et al. have improved our ability to understand and predict those changes? Finally, under current projections and trajectories, many regions of the world in 2050 will be experiencing large shifts in precipitation regimes. Thinking of Carey et al., how will this affect weathering processes, riverfloodplain interactions, and diffuse nutrient inputs from the expanded agricultural operations of 2050 ? With publication of

\section{REFERENCES}

Coumou, D., and Rahmstorf, S. (2012). A decade of weather extremes. Nat. Clim. Change 2, 491-496. doi: 10.1038/nclimate1452

Easterling, D. R., Karl, T. R., and Gallo, K. P. (2000). Observed climate variability and change of relevance to the biosphere. J. Geophys. Res. 105, 20101-20114. doi: 10.1029/2000JD900166

Elser, J. J., Sterner, R. W., Gorokhova, E., Fagan, W. F., Markow, T. A., Cotner, J. B., et al. (2000). Biological stoichiometry from genes to ecosystems. Ecol. Lett. 3, 540-555. doi: 10.1111/j.1461-0248.2000.00185.x

Figueres, C., Schellnhuber, H. J., Whiteman, G., Rockström, J., Hobley, A., and Rahmstorf, S. (2017). Three years to safeguard our climate. Nature 546, 593-595. doi: 10.1038/546593a

Hagedorn, G., Loew, T., Seneviratne, S. I., Lucht, W., Beck, M-L., Hesse, J., et al. (2019). The concerns of the young protesters are justified: A statement by Scientists for Future concerning the protests for more climate protection. GAIA Ecol. Perspect. Sci. Soc. 28, 79-87. doi: 10.14512/gaia.28.2.3

Hessen, D. O., and Elser, J. J. (2005). Elements of ecology and evolution. Oikos 109, 3-5. doi: 10.1111/j.0030-1299.2005.14055.x

IPCC (2018). "Summary for policymakers," in Global Warming of $1.5^{\circ} \mathrm{C}$. An IPCC Special Report on the Impacts of Global Warming of $1.5^{\circ} \mathrm{C}$ Above Pre-industrial Levels and Related Global Greenhouse Gas Emission Pathways, in the Context of Strengthening the Global Response to the Threat of Climate Change, Sustainable Development, and Efforts to Eradicate Poverty, eds V. Masson-Delmotte, P. Zhai, H.-O. Pörtner, D. Roberts, J. Skea, P.R. Shukla, A. Pirani, W. MoufoumaOkia, C. Péan, R. Pidcock, S. Connors, J.B.R. Matthews, Y. Chen, X. Zhou, M.I. this Research Topic we call on scientists of 2054 to remember these efforts and keep the spirit of Woodstock and Woodstoich alive so that innovation can continue to navigate the perils of a changing planet and a changing society.

\section{AUTHOR CONTRIBUTIONS}

ME-W and JE organized the Woodstoich IV Workshop. ME-W contributed initial editorial draft, and finalized the editorial manuscript. ZC, JS, JU, and JE revised the material and contributed working group summaries.

\section{FUNDING}

The Woodstoich workshop was supported by the US National Science Foundation (DEB-1840408).

\section{ACKNOWLEDGMENTS}

We are grateful to the Woodstoich 4 participants for their efforts and good spirits during the event. We thank Joseph Vanderwall and all the staff of the Flathead Lake Biological Station for their efforts in supporting the workshop. We are especially grateful to the 15 external reviewers who returned their reviews within the requested $24-\mathrm{h}$ turnaround period.

Gomis, E. Lonnoy, T. Maycock, M. Tignor, and T. Waterfield (Geneva: World Meteorological Organization), 32.

Riahi, K., Rao, S., Krey, V., Cho, C., Chirkov, V., Fischer, G., et al. (2011). RCP 8.5-A scenario of comparatively high greenhouse gas emissions. Clim. Change 109:33. doi: 10.1007/s10584-011-0149-y

Sterner, R. W., Hood, J. M., Kearney, M. R., Urabe, J., and Raubenheimer, D. (2015). Couples that have chemistry: when ecological theories meet. Oikos 124, 917-919. doi: 10.1111/oik.02672

UNCC (2019). Climate Action and Support Trends. Available online at: https:// unfccc.int/sites/default/files/resource/Climate_Action_Support_Trends_2019. pdf

Urabe, J., Naeem, S., Raubenheimer, D., Elser, J. J. (2010). The evolution of biological stoichiometry under global change. Oikos 119, 734-740. doi: 10.1111/j.1600-0706.2009.18596.x

Conflict of Interest: The authors declare that the research was conducted in the absence of any commercial or financial relationships that could be construed as a potential conflict of interest.

Copyright (C) 2019 Evans-White, Cardon, Schweitzer, Urabe and Elser. This is an open-access article distributed under the terms of the Creative Commons Attribution License (CC BY). The use, distribution or reproduction in other forums is permitted, provided the original author(s) and the copyright owner(s) are credited and that the original publication in this journal is cited, in accordance with accepted academic practice. No use, distribution or reproduction is permitted which does not comply with these terms. 